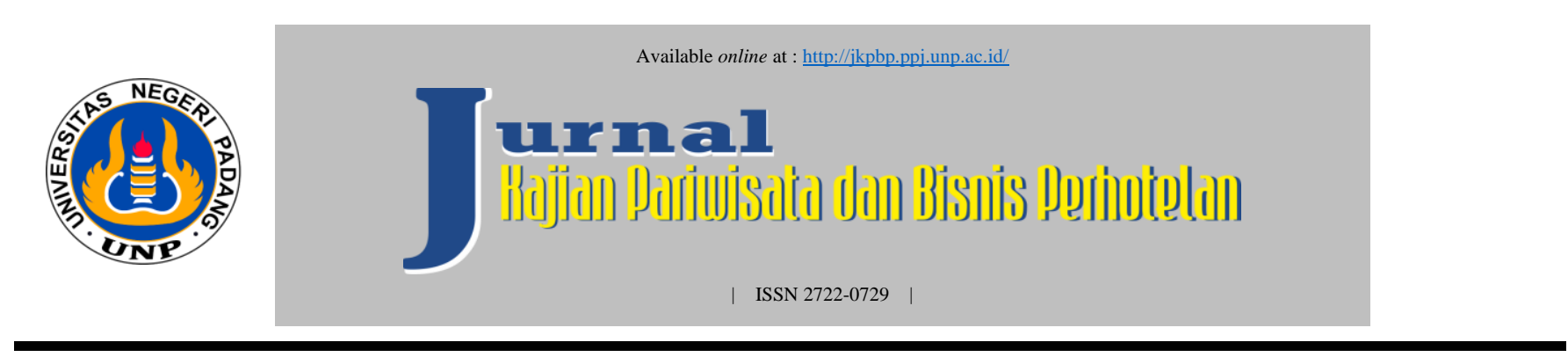

\title{
Persepsi Pengunjung Tentang Sapta Pesona di Objek Wisata Pantai Carocok Painan
}

\author{
Renggi Okta Putra ${ }^{1}$, Lise asnur ${ }^{2}$ \\ ${ }^{1}$ Universitas Negeri Padang \\ ${ }^{2}$ Universitas Negeri Padang \\ email : renggioktaputra2099@gmail.com, lise.asnur@fpp.unp.ac.id
}

\begin{abstract}
ABSTRAK
Latar belakang penelitian ini karena kurangnya penerapan sapta pesona di kawasan objek wisata pantai Carocok Painan. Penelitian ini mempunyai tujuan untuk melihat bagaimana Persepsi Pengunjung Tentang Sapta Pesona di Objek Wisata Pantai Carocok Painan. Judul dari penelitian ini adalah Persepsi Pengunjung Tentang Sapta Pesona di Objek Wisata Pantai Carocok Painan. Jenis penelitian ini yaitu deskriptif kuantitatif dengan populasi berdasarkan data kunjungan dalam rentang September 2020 sampai Februari 2021 sebanyak 26.224 orang. Adapun teknik yang dipakai yaitu non probability sampling dengan mendapatkan jumlah sampel 100 orang. Data- data dikumpulkan memakai kuisioner yang disusun menggunakan skala likert dan dilakukan uji validitas serta realibiltasnya. Kemudian datanya diolah menggunakan program SPSS 20.00. Adapun hasil dari penelitian Persepsi Pengunjung Tentang Sapta Pesona di Objek Wisata Pantai Carocok Painan masuk kedalam kategori baik dengan persentase $46 \%$. Sedangkan masing-masing indikator yaitu: (1) Aman termasuk kedalam golongan kategori sangat baik dengan persentase $62 \%$. (2) Tertib termasuk kedalam golongan kategori sangat buruk dengan persentase 59\%. (3) Bersih termasuk kedalam golongan kategori buruk dengan persentase 46\%. (4) Sejuk termasuk kedalam golongan kategori sangat baik dengan persentase 62\%. (5) Indah termasuk kedalam golongan kategori sangat baik dengan persentase 68\%. (6) Ramah termasuk kedalam golongan kategori buruk dan sangat buruk dengan masing-masing persantase 40\%. (7) Kenangan termasuk kedalam golongan kategori sangat baik dengan persentase $76 \%$.
\end{abstract}

Kata kunci : Persepsi, Sapta Pesona 


\section{PENDAHULUAN}

Pariwisata merupakan salah satu faktor pendorong berkembangnya suatu daerah. Menurut [1] Pariwisata merupakan perjalanan yang dilakukan seseorang atau kelompok yang bersifat fana demi suatu cara mengejar kepuasan di suatu tempat. Dalam kepariwisataan pengelolaan destinasi wisata dapat dikatakan baik dan teratur apabila sudah diterapkannya sapta pesona pada kawasan wisata tersebut. [2] sapta pesona merupakan kondisi yang harus diwujudkan dalam rangka menarik wisatawan agar berkunjung ke suatu kawasan objek wisata Sumatera Barat merupakan suatu provinsi yang mememiliki keadaan alam yang sangat menarik dikarenakan provinsi Sumatera Barat dikelilingi oleh perbukitan yang disebut bukit barisan, salah satu daerahnya yang memiliki potensi terbaik dalam pengembangan wisata adalah Kabupaten Pesisir Selatan.

Kabupaten Pesisir Selatan termasuk 19 daerah kabupaten terletak di Sumatera Barat tepatnya ada di bagian selatan provinsi ini dengan mempunyai ibukotanya sendiri yaitu menurut BPS Kabupaten Pesisir Selatan tahun 2015. Salah satu kawasannya yang dapat berpotensi dikembangkan menjadi destinasi unggulan adalah kawasan wisata pantai carocok painan disebelah barat kota painan sendiri. Kawasan objek wisata ini mempunyai jarak $2 \mathrm{~km}$ dari pusat Pasar Painan, dari Kota Padang sendiri objek wisata ini mempunyai jarak lebih kurang $77 \mathrm{~km}$ atau bisa ditempuh 2 jam perjalanan melalui darat. Berdasarkan hasil observasi yang penulis lakukan dan beberapa komentar pengunjung di sosial media terdapat beberapa permasalahan pada objek wisata pantai Carocok Painan tersebut, masih terdapatnya sampah-sampah berserakan di pinggiran warung mulai dari sampah plastik sampai sampah kertas sisa dari pengunjung objek wisata Pantai Carocok Painan tidak sesuai dengan unsur (bersih). Seharusnya objek wisata harus memerhatikan kebersihan di sekitar kawasan objek wisata agar pengunjung merasa nyaman dalam melakukan kunjungan.

Area parkir yang ada di objek wisata ini mempunyai tatanan yang berantakkan ini tidak sesuai dengan unsur (tertib). Peneiliti juga menemukan bahwa tatanan parkir yang berada dikawasan objek wisata tersebut terkesan berantakkan, hal ini juga ditemukan dari berbagai komentar pengunjung di sosial media. Seharusnya pihak pengelola objek wisata harus memerhatikan sistem tatatanan parkir di sekitaran objek wisata agar pengunjung lebih leluasa dalam menikmati kawasan wisata tersebut. Tentu hal ini tidak sesuai dengan unsur (tertib) pada kawasan objek wisata tersebut yang akhirnya menimbulkan kerugian bagi lahan wisata, penataan warung yang masih jauh dari kata rapi, dimana masyarakat disekitar objek wisata melakukan aktivitas dagang di sembarang tempat, hal ini juga merugikan bagi pengunjung maupun pengelola objek wisata, karna tidak sesuai dengan unsur (tertib) pada kawasan objek wisata tersebut. Seharusnya pihak ketertiban seperti satpol PP ditugaskan dalam hal ini untuk menjaga ketertiban di sekitar kawasan objek wisata tersebut, dan Penjaga gerbang yang ditemukan penulis dalam melakukan observasi kurang ramah dan tidak menggunakan seragam dalam melayani pengunjung yang masuk ke kawasan objek wisata Pantai Carocok Painan, ini tidak sesuai dengan unsur (ramah tamah). Seharusnya pihak pengelola objek wisata memberikan pengarahan bagi penjaga gerbang dalam melakukan pelayanan kepada pengunjung dan memberikan seragam agar terlihat lebih professional supaya meminimalisir komplain dari pengunjung yang datang. Aspek penting yang mendasar bagi perkembangan destinasi pariwisata dalam pengembangan wisata yang baik disuatu objek wisata ialah sketsa yang mencerminkan adanya keikut sertaan dan dukungan sekelompok masyarakat, pengelola objek wisata serta campur tangan kedinasan pemda seperti dinas pariwisata pemuda dan olahraga agar dapat menunjang keberhasilan penerapan Sapta Pesona pada kawasan objek wisata Pantai Carocok Painan ini supaya terciptanya kawasan objek wisata yang sesuai dengan standar Sapta Pesona.

Mengikuti masalah yang dipaparkan, menarik kesimpulan yaitu penerapan sapta pesona ini harusnya lebih diterapkan lagi pada kawasan wisata Pantai Carocok Painan. Jika penerapan ini berhasil diberlakukan maka menarik kesimpulan seperti lebih meeningkat kunjungan dan 
memberikan manfaat bagi perekonomian masyarakat yang tinggal disekitar objek wisata. Adapun tujuan penelitian ini dilakukan supaya melihat bagaimana persepsi pengunjung tentang sapta pesona dari indikator sapta pesona yaitu aman, tertib, bersih, sejuk, indah, ramah dan kenangannya.

\section{METODOLOGI}

Jenis penelitian yang digunakan adalah deskriptif kuantitatif. Menurut [3] metode kuantitatif dapat diartikan sebagai metode penelitian berdasarkan pada filsafat positivism, diberlakukan untuk meneliti populasi atau sampel terpilih, pengumpulan data melalui instrument penelitian, analisis data bersifat kuantitatif/statistik yang bertujuan untuk menggambarkan dan mengukur hipotesis yang sudah ditetapkan. Populasi berdasarkan data kunjungan dalam rentang September 2020 sampai Februari 2021 sebanyak 26.224 orang. Metode dalam penelitian ini menggunakan jenis non probabilitik sampling dengan teknik yang dipakai accidental sampling. Jumlah sampel di penelitian ini 100 pengunjung.

\section{HASIL DAN PEMBAHASAN}

\section{a. Deskripsi Data Variabel Sapta Pesona(X)}

Jumlah pernyataannya 34 butir yang sudah dilakukan uji valid dan reliabilitasnya. Disebarkan ke sampel sebanyak 100 orang yang tersusun dari 7 indikator.

\section{Tabel 1. Pendistribusi Frekuensi Data Sapta Pesona(X)}

\begin{tabular}{|c|c|c|c|}
\hline Kategori & Rentang Skor & Frekuensi & Persentase \% \\
\hline Sangat Baik & $>136$ & 9 & 9 \\
\hline Baik & $\mathbf{1 1 3 , 3 3 < \mathbf { 1 3 6 }}$ & $\mathbf{4 6}$ & $\mathbf{4 6}$ \\
\hline Cukup & $90,67<113,33$ & 10 & 10 \\
\hline Buruk & $68,01<90,67$ & 16 & 16 \\
\hline Sangat Buruk & $<68,01$ & 19 & 19 \\
\hline \multicolumn{2}{|r|}{ Jumlah } & 100 & 100 \\
\hline
\end{tabular}

Sumber: data olahan pribadi (2021)

Hasil dari 100 orang sampel dapat dilihat: Kategori baik mempunyai nilai yang tinggi dalam rentang 113,33 < 136 dengan nilai 46\% selanjutnya pada urutan berikutnya ada kategori sangat buruk 19\%, buruk 16\%, cukup 10\% dan sangat baik $9 \%$.

Selanjutnya data masing masing indikator sebagai berikut:

\section{1) Aman}

Tabel 2. Pendistribusian Data Indikator Aman

\begin{tabular}{|c|c|c|c|}
\hline Kategori & Rentang Skor & Frekuensi & Persentase \% \\
\hline Sangat Baik & $>\mathbf{1 9 , 9 9}$ & $\mathbf{6 2}$ & $\mathbf{6 2}$ \\
\hline Baik & $16,66<19,99$ & 0 & 0 \\
\hline Cukup & $13,33<16,66$ & 1 & 1 \\
\hline Buruk & $10<13,33$ & 16 & 16 \\
\hline Sangat Buruk & $<10$ & 21 & 21 \\
\hline \multicolumn{2}{|c|}{ Jumlah } & 100 & 100 \\
\hline
\end{tabular}


Hasil dari paparan diatas menunjukkan rentang $>19,99$ memiliki nilai yang paling tinggi dengan $62 \%$ selanjutnya diikuti rentang $<10$ dengan nilai $21 \%, 10<13,33$ dengan $16 \%, 13,33<16,66$ dengan $1 \%$ dan rentang $16,66<19,99$ dengan nilai $0 \%$.

2) Tertib

Tabel 3. Pendistribusian Data Indikator Tertib

\begin{tabular}{|c|c|c|c|}
\hline Kategori & Rentang Skor & Frekuensi & Persentase \% \\
\hline Sangat Baik & $>19,99$ & 6 & 6 \\
\hline Baik & $16,66<19,99$ & 3 & 3 \\
\hline Cukup & $13,33<16,66$ & 0 & 0 \\
\hline Buruk & $10<13,33$ & 32 & 32 \\
\hline Sangat Buruk & $<\mathbf{1 0}$ & $\mathbf{5 9}$ & $\mathbf{5 9}$ \\
\hline \multicolumn{2}{|c|}{ Jumlah } & 100 & 100 \\
\hline
\end{tabular}

Hasil dari paparan tabel mempunyai nilai yang paling tinggi adalah kategori sangat buruk dengan nilai 59\% selanjutnya buruk dengan nilai $32 \%$, sangat baik $6 \%$, baik $3 \%$ dan cukup dengan nilai $0 \%$.

3) Bersih

Tabel 4Tabel 4. Pendistribusian Data Indikator Bersih

\begin{tabular}{|c|c|c|c|}
\hline Kategori & Rentang Skor & Frekuensi & Persentase \% \\
\hline Sangat Baik & $>19,99$ & 9 & 9 \\
\hline Baik & $16,66<19,99$ & 0 & 0 \\
\hline Cukup & $13,33<16,66$ & 5 & 5 \\
\hline Buruk & $\mathbf{1 0}<\mathbf{1 3 , 3 3}$ & $\mathbf{4 6}$ & $\mathbf{4 6}$ \\
\hline Sangat Buruk & $<10$ & 40 & 40 \\
\hline \multicolumn{2}{|c|}{ Jumlah } & 100 & 100 \\
\hline
\end{tabular}

Hasil dari tabel diatas menunjukkan kategori buruk dengan nilai tertinggi yaitu 46\%, selanjutnya ada sangat buruk dengan nilai $40 \%$, sangat baik dengan $9 \%$, cukup dengan $5 \%$ dan baik sebanyak $0 \%$.

4) Sejuk

Tabel 5. Pendistribusian Data Indikator Sejuk

\begin{tabular}{|c|c|c|c|}
\hline Kategori & Rentang Skor & Frekuensi & Persentase \% \\
\hline Sangat Baik & $>\mathbf{1 9 , 9 9}$ & $\mathbf{6 2}$ & $\mathbf{6 2}$ \\
\hline Baik & $16,66<19,99$ & 0 & 0 \\
\hline Cukup & $13,33<16,66$ & 1 & 1 \\
\hline Buruk & $10<13,33$ & 16 & 16 \\
\hline Sangat Buruk & $<10$ & 21 & 21 \\
\hline \multicolumn{2}{|c|}{ Jumlah } & 100 & 100 \\
\hline
\end{tabular}

Hasil dari paparan tabel nya yaitu sangat baik dengan nilai maksimal $62 \%$ diikuti sangat buruk dengan $21 \%$, buruk $16 \%$, cukup $1 \%$ dan baik dengan nilai $0 \%$. 


\section{5) Indah}

Tabel 6. Pendistribusian Data Indikator Indah

\begin{tabular}{|c|c|c|c|}
\hline Kategori & Rentang Skor & Frekuensi & Persentase \% \\
\hline Sangat Baik & $>\mathbf{1 9 , 9 9}$ & $\mathbf{6 8}$ & $\mathbf{6 8}$ \\
\hline Baik & $16,66<19,99$ & 1 & 1 \\
\hline Cukup & $13,33<16,66$ & 1 & 1 \\
\hline Buruk & $10<13,33$ & 13 & 13 \\
\hline Sangat Buruk & $<10$ & 17 & 17 \\
\hline \multicolumn{2}{|c|}{ Jumlah } & 100 & 100 \\
\hline
\end{tabular}

Hasil paparan tabelnya menunjukkan kategori sangat baik dengan nilai tinggi sebesar $68 \%$, selanjutnya ada sangat buruk dengan nilai $17 \%$, buruk $13 \%$, cukup dan baik dengan nilai yang sama sebesar $1 \%$.

6) Ramah

Tabel 7. Pendistribusian Data Indikator Ramah

\begin{tabular}{|c|c|c|c|}
\hline Kategori & Rentang Skor & Frekuensi & Persentase \% \\
\hline Sangat Baik & $>15,99$ & 9 & 9 \\
\hline Baik & $13,33<15,99$ & 0 & 0 \\
\hline Cukup & $10,67<13,33$ & 11 & 11 \\
\hline Buruk & $\mathbf{8 , 0 1}<\mathbf{1 0 , 6 7}$ & $\mathbf{4 0}$ & $\mathbf{4 0}$ \\
\hline Sangat Buruk & $<\mathbf{8 , 0 1}$ & $\mathbf{4 0}$ & $\mathbf{4 0}$ \\
\hline \multicolumn{2}{|c|}{ Jumlah } & 100 & 100 \\
\hline
\end{tabular}

Hasil paparan indikator ramah mempunyai nilai $40 \%$ masing masing kategori dengan nilai tinggi yaitu buruk dan sangat buruk selanjutnya ada kategori cukup dengan nilai $11 \%$, sangat baik $9 \%$ dan baik dengan nilai $0 \%$.

7) Kenangan

Tabel 8. Pendistribusian Data Indikator Kenangan

\begin{tabular}{|c|c|c|c|}
\hline Kategori & Rentang Skor & Frekuensi & Persentase \% \\
\hline Sangat Baik & $>\mathbf{1 9 , 9 9}$ & $\mathbf{7 6}$ & $\mathbf{7 6}$ \\
\hline Baik & $16,66<19,99$ & 0 & 0 \\
\hline Cukup & $13,33<16,66$ & 0 & 0 \\
\hline Buruk & $10<13,33$ & 11 & 11 \\
\hline Sangat Buruk & $<10$ & 13 & 13 \\
\hline \multicolumn{2}{|c|}{ Jumlah } & 100 & 100 \\
\hline
\end{tabular}

Hasil dari paparan tabel diatas menunjukkan nilai maksimal pada kategori sangat baik dengan nilai $76 \%$ selanjutnya sangat buruk $13 \%$, buruk $11 \%$, serta baik dan cukup dengan nilai sama-sama $0 \%$ 


\section{Pembahasan}

Merujuk pada hasil dari penelitian mengenai judul dari penelitian ini dapat dilihat sebagai berikut:

1) Aspek Aman

Hasil dari data indikator aman berada pada kategori sangat baik dengan nilai $62 \%$. Maka ditarik kesimpulan bahwa pengunjung puas kepada aspek aman di kawasan wisata ini, maka dengan terjaminnya keamanan pengunjung dalam berwisata dapat dijadikan peluang dalam peningkatan pengunjung di kawasan objek wisata ini, hal tersebut juga sejalan dengan pendapat [4] Faktor kenyamanan dan keamanan di suatu kawasan pariwisata merupakan nilai tambahan dan peluang untuk dikunjungi oleh pengunjung.

\section{2) Aspek Tertib}

Hasil penelitian menunjukkan bahwa persentase tertinggi pada indikator tertib berada pada kategori sangat buruk dengan persentase 59\%. Ditarik hasil bahwa sebagian besar responden tidak puas terhadap aspek aman di Objek Wisata Pantai Carocok Painan, hal ini menjadi peringatan bagi pengelola Objek Wisata Pantai Carocok Painan serta semua kalangan yang terlibat dalam pengelolan kawasan objek wisata ini, seharusnya dalam menjalankan pengelolan objek wisata yang baik direncanakan dengan perencanaan yang tersusun agar tidak mendapat nilai rendah di mata pengunjung, hal ini sesuai dengan yang dikemukakan [5] Perencanaan menjadi hal pertama dari pelaksanaan suatu sistem manajemen.

\section{3) Aspek Bersih}

Hasil penelitian menunjukkan bahwa persentase tertinggi pada indikator bersih berada pada kategori buruk dengan persentase 46\%. Maka dapat disimpulkan bahwa sebagian besar responden tidak puas terhadap kebersihan di kawasan Objek Wisata Pantai Carocok Painan. Objek wisata ini dinilai kurang bersih karena kurangnya pengelola dalam melaksanakan tugas dan tanggung jawabnya dalam menjaga kebersihan serta dengan masyarakat yang mendirikan warung disekitar objek wisata kurang dalam memerhatikan sampah disekitar warungnya.

\section{4) Aspek Sejuk}

Hasil penelitian menunjukkan bahwa persentase tertinggi pada indikator sejuk berada pada kategori sangat baik dengan persentase 62\%. Diambil hasil bahwa sebagian besar responden menyatakan puas terhadap kesejukkan di Objek Wisata Pantai Carocok Painan, tingkat kesejukkan dari kawasan wisata memang harus dijaga dan dilestarikan oleh pengelola objek wisata tersebut, melalui tingkat kesejukkan dan penataan yang baik dapat menghasilkan dampak yang positif bagi perkembangan objek wisata.

\section{5) Aspek Indah}

Hasil data indikator ramah menempati kategori sangat baik dengan niali 68\%. Setelah itu diambil kesimpulan pengunjung puas kepada segi indah dari kawasan wisata ini. Keindahan pada suatu kawasan wisata dapat memberikan banyak manfaat bagi pengelola maupun pengunjung yang berkunjung ke objek wisata tersebut. Dari hasil yang diperoleh, keindahan pada objek wisata pantai carocok painan sudah menuai hasil yang sangat baik dari pengunjung. Hal ini harus dipertahankan oleh pihak pengelola dan segala pihak yang berkaitan dengan objek wisata ini untuk menunjang tingkat kunjungan pengunjung objek wisata.

\section{6) Aspek Ramah}

Hasil penelitian menunjukkan bahwa persentase tertinggi pada indikator ramah berada kategori buruk dan sangat buruk, dengan persentase masing-masing kategori berada pada 40\%. Ditarik hasil bahwa pengunjung menyatakan tidak puas terhadap keramah-tamahan pelaku wisata atau pengelola wisata di Objek Wisata Pantai Carocok Painan. Keadaan seperti ini harus lebih diperhatikan lagi bagi beberapa pihak pengelola maupun pihak yang 
menyangkut atas perkembangan objek wisata ini, jika hal ini tidak diperhatikan maka penerapan sapta pesona di objek wisata pantai carocok painan tidak dapat tercapai. Karena keramah-tamahan dapat menjadikan perasaan nyaman dan betah bagi pengunjung dalam berkunjung ke suatu objek wisata hal ini selaras seperti yang tercantum di [6] Masyarakat di kawasan pariwisata yang mencerminkan situasi akrab, mewujudkan perasaan nyaman, perasaan diterima dan betah (seperti rumah sendiri) bagi pengunjung.

\section{7) Aspek Kenangan}

Hasil penelitian menunjukkan bahwa persentase tertinggi pada indikator kenangan berada kategori sangat baik, dengan persentase pada 76\%. Diambil hasil bahwa pengunjung merasa puas terhadap aspek kenangan di Objek Wisata Pantai Carocok Painan. Kenangan atau cinderamata di objek wisata ini sudah bagus pengelolan nya dan banyak diminati oleh pengunjung yang datang sebagai buah tangan dari kunjungannya.

\section{KESIMPULAN}

Hasil penelitiannya menyatakan bahwa: tingkat capaian persepsi pengunjung tentang sapta pesona di objek wisata pantai carocok painan termasuk kedalam kategori baik dengan nilai persentase 46\%. Termasuk 7 indikator dengan capaian sebagai berikut :

Aman kedalam kategori sangat baik dengan nilai persentase $62 \%$, tertib kedalam kategori sangat buruk dengan nilai persentase 59\%, bersih kedalam kategori buruk dengan nilai persentase $46 \%$, sejuk kedalam kategori sangat baik dengan nilai persentase $62 \%$, indah kedalam kategori sangat baik dengan nilai persentase $68 \%$, ramah kedalam kategori buruk dan sangat buruk dengan nilai persantese masing-masing $40 \%$, dan kenangan kedalam kategori sangat baik dengan persentase $76 \%$. 


\section{DAFTAR PUSTAKA}

[1] Wahid, Abdul. Strategi Pengembangan Wisata Nusa Tenggara Barat Menuju Destinasi Utama Wisata Islami. Skripsi, 2015.

[2] Riawan, A., \& Indraphrasta, D. E. A. The Role of Sapta Pesona Wisata in Increasing The Revenue of Tourism Industry Entrepreneurs at The South Bantul Beaches. Khasanah IlmuJurnal Pariwisata Dan Budaya, 8(2), 2017

[3] Sugiyono. Metedologi Penelitian Kuantitatif. Bandung: Alfabeta. 2018

[4] Khalik, W. Kajian Kenyamanan dan Keamanan Wisatawan di Kawasan Pariwisata Kuta Lombok. Jurnal Master Pariwisata (JUMPA), 2014.

[5] Nitisusastro, M. Perilaku Konsumen dalam Perspektif Kewirausahaan. Bandung: Alfabeta, 2012.

[6] Wisata, P. K. S.. Jakarta: Kementrian Pariwisata dan Ekonomi Kreatif, 15, 2012. 